Ashkanfar A, Langton DJ, Joyce TJ.

A large taper mismatch is one of the key factors behind high wear rates and failure at the taper junction of total hip replacements: A finite element wear analysis.

Journal of the Mechanical Behavior of Biomedical Materials (2017)

DOI: http://dx.doi.org/10.1016/j.jmbbm.2017.01.018

\section{Copyright:}

(C) 2017. This manuscript version is made available under the CC-BY-NC-ND 4.0 license

DOI link to article:

http://dx.doi.org/10.1016/j.jmbbm.2017.01.018

Date deposited:

$16 / 01 / 2017$

Embargo release date:

12 January 2018

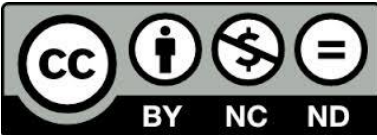

This work is licensed under a

Creative Commons Attribution-NonCommercial-NoDerivatives 4.0 International licence 


\section{Author's Accepted Manuscript}

A large taper mismatch is one of the key factors behind high wear rates and failure at the taper junction of total hip replacements: A finite element wear analysis

Ariyan Ashkanfar, David J. Langton, Thomas J. Joyce

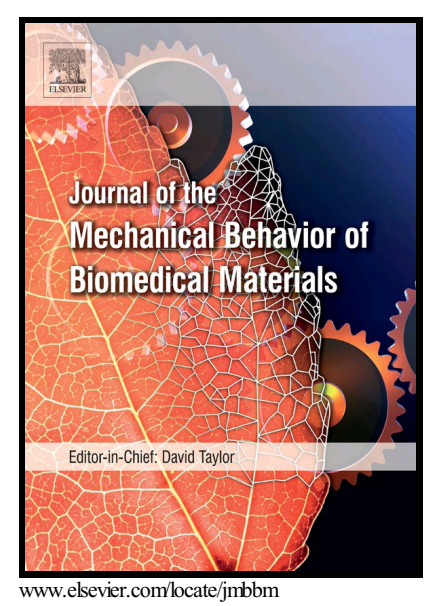

PII: $\quad$ S1751-6161(17)30025-5

DOI: $\quad$ http://dx.doi.org/10.1016/j.jmbbm.2017.01.018

Reference: JMBBM2189

To appear in: Journal of the Mechanical Behavior of Biomedical Materials

Received date: 5 July 2016

Revised date: 29 November 2016

Accepted date: 11 January 2017

Cite this article as: Ariyan Ashkanfar, David J. Langton and Thomas J. Joyce, A large taper mismatch is one of the key factors behind high wear rates and failur at the taper junction of total hip replacements: A finite element wear analysis Journal of the Mechanical Behavior of Biomedical Materials http://dx.doi.org/10.1016/j.jmbbm.2017.01.018

This is a PDF file of an unedited manuscript that has been accepted fo publication. As a service to our customers we are providing this early version o the manuscript. The manuscript will undergo copyediting, typesetting, an review of the resulting galley proof before it is published in its final citable form Please note that during the production process errors may be discovered whic could affect the content, and all legal disclaimers that apply to the journal pertain 


\title{
A large taper mismatch is one of the key factors behind high wear rates and failure at the taper junction of total hip replacements: A finite element wear analysis
}

\author{
Ariyan Ashkanfar ${ }^{*}$, David J. Langton ${ }^{2}$, Thomas J. Joyce ${ }^{1}$ \\ ${ }^{1}$ School of Mechanical and Systems Engineering, Newcastle University, Stephenson Building, \\ Claremont Road, Newcastle Upon Tyne, NE1 7RU, UK. \\ ${ }^{2}$ North Tees Explant Centre (NTEC), University Hospital of North Tees, North Tees, UK.
}

\begin{abstract}
Total hip replacement (THR) is one of the most successful orthopaedic surgeries; however, failures can occur due to adverse reactions to wear debris. Recently, a large number of failures linked to the release of metal particles from the taper junction between femoral head and femoral stem have been reported. One possible reason for this may be design variations such as taper mismatches associated with the taper and trunnion angles. Could a large taper mismatch lead to inappropriate contact mechanics and increase relative micromotion and thus wear? In this study, 3D finite element (FE) models of a commercial THR from a perfectly matched interface to large taper mismatches and a wear algorithm were used to investigate the extent of wear that could occur at this junction and identify the optimum tolerances in order to reduce the wear. A co-ordinate measuring machine (CMM) was used to analyse the wear depth and volumetric wear rate of the tapers of 54 explanted $36 \mathrm{~mm}$ diameter Cobalt Chromium femoral heads, which had been in service for 5.1 years in average, to validate the FE analyses. It was found that a large taper mismatch (e.g. 9.12' ) results in a high wear rate $\left(2.960 \mathrm{~mm}^{3}\right.$ per million load cycles). Such wear rates can have a major negative effect on the clinical outcomes of these implants. It was also found that even a slight reduction in mismatch significantly reduced the magnitude of the wear rates $\left(0.069 \mathrm{~mm}^{3}\right.$ per million load cycles on average for $6^{\prime}$ taper mismatch). It is recommended that the cone angles of femoral head and femoral trunnion should be manufactured to produce a taper mismatch of less than $6^{\prime}$ at the taper junction.
\end{abstract}

Keywords: wear modelling, finite element analysis, total hip replacement, taper mismatch, taper angle, trunnion angle

\footnotetext{
* Corresponding author. Tel: +44 759198 0781. E-mail address: ariyan.ashkanfar@newcastle.ac.uk, ariyan.ashkanfar@gmail.com (A. Ashkanfar).
} 


\section{Introduction}

A total hip replacement (THR) usually consists of a femoral stem, a femoral head, and an acetabular liner which fits inside an acetabular shell. In some cases, such as large head metal-on-metal (MoM) hips, the acetabular component can be a single piece, 'monoblock', acetabular cup. The femoral stem is fitted into the medullary cavity of the femur and, if cementless fixation is considered, is usually made from titanium, Ti-6Al-4V, (Ti). The femoral head is generally made from either a cobalt-chromium, $\mathrm{Co}-28 \mathrm{Cr}-6 \mathrm{Mo},(\mathrm{CoCr})$ or a ceramic material. Again considering cementless fixation, the acetabular components consist of a Ti outer shell with a liner of $\mathrm{CoCr}$ (MoM THR), ceramic (ceramic-on-ceramic (CoC) THR) or polyethylene (metal-on-polyethylene (MoP) THR).

THR is recognised as one of the most successful orthopaedic surgeries; however, failures mainly due to wear and, to a lesser extent, due to loosening, fracture or infection - do occur (2016). Specifically, the MoM material combinations have recently fallen in popularity of use due to a relatively large number of early failures associated with adverse reactions to metal debris (Anissian et al., 1999; Brock et al., 2015). This unacceptably high failure rate is mainly associated with wear that occurs at the articulating (Brock et al., 2015; Joyce et al., 2009; Lord et al., 2011) and non-articulating (Langton et al., 2012; Matthies et al., 2013) surfaces of these medical implants.

There have also been reports of adverse reactions to metal debris due to metallic wear debris produced from the taper junction for MoP THR (Cooper et al., 2012; Lindgren et al., 2011; Mao et al., 2012). The taper junction of the THR, which is the focus of this study, is the interface between the internal taper of the modular femoral head and the trunnion of the femoral stem (see Figure 1) where the surgeon impacts the head onto the femoral stem during surgery. While the hip prosthesis is in service, the taper junction interface will be subjected to micromotion (Atwood et al., 2010; Hallab et al., 2004), which can lead to the release of metal debris due to fretting wear.

Design and manufacturing variations could have an effect on the amount of material lost from the taper junction while the hip prosthesis is in the body. Based on explant studies, these variations, such as surface roughness, have been shown to be significant factors in wear and metal debris release from this junction (Brock et al., 2015; Langton et al., 2012).

Panagiotidou et al. (2013) showed that while the hip prosthesis is in service, the surface roughness of the trunnion increases if mated with a rough taper, which led to greater material 
release from the taper junction. Brock et al. (2015) also showed high volumetric wear rates for the taper of explanted $\mathrm{CoCr}$ heads and hypothesised that a rougher taper surface could increase the wear rates at this taper junction. Jani et al. (1997) showed that taper variations such as taper design and taper surface finish have a significant impact on the fretting behaviour at the THR taper junction. Femoral head offsets are also known to likely have an effect on the generation of wear debris at the taper junction (McGrory et al., 1995).

Langton et al. (2012) have shown varus stems, larger head diameters and head offsets increase the horizontal moment arm acting at the taper junction, which increases the fretting wear rate at this junction. They further showed a wide variation in the manufacturing tolerances of the taper and trunnion angles of one manufacturer's THRs (Langton et al., 2016). They analysed 93 retrieved head tapers and found that many of the tapers had not been manufactured to specifications. They also analysed the surface roughness of 10 new sterile femoral head taper components (Articuleze), showing a high variation in the Ra value (0.191.80 microns), and concluding that higher Rpk values (the average height of the protruding peaks above the roughness) are undesirable as they are linked with increased wear. This finding corresponded with a study by Munir et al. (2015) who also found a great variation in the surface finish of the femoral head taper (0.14-4.20 microns Ra values). They too hypothesised that increased metal debris generation from the taper junction could be associated with this surface roughness variation and also with a taper-trunnion angular mismatch.

These studies therefore highlight that the taper-trunnion mismatch angle could have a significant effect on generation of the metallic debris at the taper junction. There is evidence that taper and trunnion tolerances are around eight-fold larger than those used in the machine tool industries (Bobyn et al., 1993; Jani et al., 1997). As published by the American Society for Testing and Materials (Marlowe et al., 1997), there are no specific standards for taper and trunnion tolerances for the orthopaedic industry and mainly manufacturers use their own.

A computational approach that could predict the effect of the design variations over time in service could demonstrate the optimum tolerances to reduce the amount of material lost and potentially increase the longevity of hip implants. In this study, we used a previously validated wear algorithm using a finite element model of a commonly used Ti femoral stem with a $36 \mathrm{~mm}$ diameter $\mathrm{CoCr}$ femoral head in order to investigate the effect of different tapertrunnion mismatches on the subsequent fretting wear at the taper junction over a period of 
time in service. A co-ordinate measuring machine (CMM) was also used to analyse the wear pattern and volumetric wear rates at the taper inside the femoral head of 54 retrieved Pinnacle prostheses (DePuy). These were selected as they consist of a $36 \mathrm{~mm}$ diameter $\mathrm{CoCr}$ femoral head and a Ti femoral stem. The aim was to investigate the effect of varying taper mismatches on the volumetric wear rates and wear damage at this junction and determine the optimum tolerances that could minimise wear rates.

\section{Method}

\subsection{Implementation of the wear law}

The "Dissipated Energy" wear law uses a single energy wear coefficient $(\alpha)$ with a wide range of stroke (50 $\mu \mathrm{m}$ to $1.3 \mathrm{~mm})$, which provides a greater range of application than Archard's wear law (Fouvry et al., 2003; Liskiewicz and Fouvry, 2005; Magaziner et al., 2008). This law considers the interfacial shear work and relative motion as predominant parameters to calculate the volumetric wear. Its implementation in finite element analysis has been explained previously (English et al., 2015). Briefly, according to the "Dissipated Energy" wear law, the cyclic wear depth $\left(W_{c}\right)$ for a single cycle of loading can be presented using Equation 1,

$W_{c}=\sum_{i=1}^{n} \alpha \tau_{i} s_{i}$

where $\alpha$ is the energy wear coefficient and, $\tau_{i}$ and $s_{i}$ are the contact shear stress and the contact slip over a specific time interval $i$ respectively. In order to reduce the number of computational analyses, it has been assumed that the cyclic wear depth will remain constant over a short period of time. This short time period is then defined as a "wear scaling factor" $(\beta)$ which takes the same cyclic wear depth at each point of contact for a larger number of loading cycles. Then, the total linear wear depth $\left(W_{d}\right)$ over an assigned total number of loading cycles $(N)$ at specific analysis stage $(j)$ and by employing a $\beta$ value can be obtained using Equation 2.

$W_{d}=\sum_{j=1}^{(N / \beta)} \beta \sum_{i=1}^{n} \alpha \tau_{i, j} S_{i, j}$

A study on the effect of $\beta$ on the calculation of wear undertaken in the previous study has demonstrated that $\beta=10^{5}$ provides converged results (English et al., 2015). However, in this 
study, by employing a new model with a more realistic boundary condition and a refined mesh at the contact area, the $\beta$ value has been converged at 250,000 load cycles, which further reduced the computational wear analysis time.

A fraction of calculated $W_{d}$ for each paired node at each analysis stage is removed from the taper and trunnion. This fraction, namely the "wear fraction", is dependent on the material interaction properties in contact. The wear fractions for a CoCr alloy head and Ti alloy stem combination have been specified as 0.9 and 0.1 respectively. This is due to preferential oxidation of the Ti alloy over the CoCr, which increases the hardness of the Ti and wears the un-oxidised CoCr, as has been published previously (Bishop et al., 2013; Bone et al., 2015; Langton et al., 2011a; Moharrami et al., 2013).

The energy wear coefficient for the CoCr alloy on the Ti alloy $\left(\alpha=1.31 \times 10^{-8} \mathrm{MPa}^{-1}\right)$ used in this study was obtained by Zhang et al. (2013) from a fretting wear test. As explained in (English et al., 2015), the Dissipated Energy wear law was applied to a wear algorithm as a custom user plug-in linked with ABAQUS (6.14-3 ABAQUS Inc) software. For this study, the algorithm has been further developed, generalised and optimised in order to reduce the computational cost. In this study, this validated algorithm was used to calculate the wear depth and obtain the volume of material loss, volumetric wear rate and the wear pattern damage at the taper junction with different taper mismatches.

\subsection{Finite element wear analysis}

A commonly used commercial Ti alloy femoral stem and a $36 \mathrm{~mm}$ diameter $\mathrm{CoCr}$ femoral head were modelled in ABAQUS (see Figure 2c). The models are identical in terms of materials and design apart from the cone angles, from a large tip- and base-locked junction to a perfectly matched interface (see Table 1). There is a wide variation in the manufacturing tolerances of the taper and trunnion angles of THRs. Langton et al. (2016) showed taper angles ranged from 5 $5^{\circ} 2^{\prime}$ to $5^{\circ} 42^{\prime}$ for 93 “Articuleze” (DePuy) femoral heads. Brock et al. (2015) showed a range of $5^{\circ} 56^{\prime}$ to $6^{\circ} 9^{\prime}$ for S-ROM (DePuy) trunnion angles and $5^{\circ} 33^{\prime}$ to $5^{\circ} 47^{\prime}$ for Corail (DePuy) trunnion angles. Varying taper angles of $5^{\circ} 34^{\prime}$ to $5^{\circ} 48^{\prime}$ and $5^{\circ} 35^{\prime}$ to $5^{\circ} 41^{\prime}$ were also measured from 63 Articular Surface Replacement (ASR, DePuy) and 48 Articuleze femoral heads respectively (Langton et al., 2012). Therefore, a possible variation of around 10' taper mismatch, associated with the taper and trunnion cone angels, could transpire when the components are coupled. As such, a series of tip- and base-locked 
models along with a perfectly matched interface were modelled as illustrated in Table 1 to investigate the effect of possible mismatches on the wear rates at the taper junction.

The models were then meshed using eight-node bilinear hexahedral reduced integration elements (C3D8R). The elements at the contact interface were matched and refined with a total of 9600 paired elements at the contact interface. This was followed by a mesh convergence study (the procedure was previously explained in (English et al., 2015)), which showed an element size of approximately $0.18 \mathrm{~mm}$ provided a converged solution so that an accurate and smooth evolution of wear was obtained. Table 1 and Figure 2 show a schematic representation of the models, loads and boundary conditions.

The computer model is able to consider the initial impaction to simulate the assembly of the head onto the stem intra-operatively as well as its weakening as the wear analysis progresses. A previous study has shown that an increase in assembly force results in a reduction in fretting wear (English et al., 2016). It was recommended that a $4 \mathrm{kN}$ initial assembly force is required to minimise the wear rates. As such, in this study an initial impaction force of $4 \mathrm{kN}$ was considered for all the models (shown in Figure 2a and c). This impaction analysis, known as "phase 1" of the wear methodology (see (English et al., 2015)) was executed as a dynamic implicit analysis at commencement of the wear analysis.

We have modified and improved the loading and boundary conditions prescribed for the FE models from the earlier study (English et al., 2015) in order to avoid creating non-physiologic resisting moments at the centre of the femoral head. In this study, the loads (superior-inferior, anterior-posterior and medial-lateral (Bergmann et al., 2001)) are applied to a reference point located at the centre of the femoral head being coupled to a surface area on the top of the head (see Figure $2 b$ and $d$ ). This area was found from the area of wear damage at the bearing surface on the majority of the retrieved femoral heads (see Figure 2 e and f). As such, the load is transferred from this area to the taper junction as shown in Figure 2d. When measured, this worn area was found to be around $35^{\circ}$ away from the central axis of the head while the head and stem are assembled at $45^{\circ}$ from the vertical axis (see Figure $2 \mathrm{~d}$ ). The rotations (flexions-extension, internal-external and adduction-abduction (Bergmann et al., 2001)) are applied to another reference point, again located at the centre of the head and coupled to the stem, which constrains the model so that it can only rotate about the centre of the head and virtually locates the head in the acetabular cup (see Figure $2 \mathrm{~b}$ and $\mathrm{d}$ ). These loading and boundary conditions create an efficient and realistic model by excluding the requirement to 
model the acetabular cup and femur bone. The loading and boundary conditions associated with a walking step (gait) are then applied to an FE dynamic implicit analysis and the step time is discretised into 10 equal time intervals over a $1.2 \mathrm{~s}$ period (Bergmann et al., 2001).

The material properties of the CoCr alloy and Ti alloy were assigned on the femoral head and femoral stem respectively shown in Table 2 . The contact interaction was modelled as finite sliding using surface to surface contact discretization method and the penalty contact formulation in ABAQUS solver with an isotropic coefficient of friction of 0.21 , based on the work by Fessler and Fricker (1989) (see Table 2).

An average of 1 million walking cycles per year has been assumed in this study; as such, the volumetric wear rates demonstrated are over 1 million walking steps (Schmalzried et al., 1998). The volumetric wear rates and total volume loss have been determined based on the reduction of element volume ("EVOL" field output from ABAQUS) for all the elements at the taper junction contact zone using a separate custom Python script linked as a user plug-in within ABAQUS.

As discussed, the wear algorithm has been optimised in this study, which runs faster than in the previous studies (English et al., 2015, 2016). The time taken for each wear analysis over 10 million walking cycles is now less than 440 hours, executed on a 64-bit Windows 7 Enterprise OS with a 12-core Intel Xeon CPU platform at $2.6 \mathrm{GHz}$ and $128 \mathrm{~GB}$ of random access memory.

The contact surface can be divided into two main areas from the centre of rotation, above and below the centre of rotation, namely upper and lower "contact surface offset" respectively (see Figure 3). This division is important, as the majority of the upper contact surface offset is under the loading area and has a shorter moment arm than the lower contact surface offset. The moment arm is calculated as the perpendicular distance from the resultant loads distributed on the bearing surface of the femoral head to each point of the contact surface. Figure 3 shows the maximum moment arm (considering an equivalent concentrated resultant force) and the moments that occur at both upper and lower contact surface offset. In this study, all the models have approximately 4 and $6 \mathrm{~mm}$ upper and lower contact surface offset respectively, based on the commonly used femoral stem mated with femoral head (see Figure $3)$. 
The interfacial shear work (product of the contact shear force and relative motion) is the key parameter for the generation of the wear. The variation of this parameter during wear analysis has already been presented in the previous studies (English et al., 2015, 2016). As such, the wear evolution is just presented here for clarity.

\subsection{Wear measurement of retrieved hip prostheses}

A co-ordinate measuring machine (CMM; Legex 322, Mitutoyo, $0.8 \mu \mathrm{m}$ accuracy) with a 0.5 mm diameter probe was used to measure the wear depth, volumetric wear loss and wear pattern of the tapers within 54 retrieved 36mm diameter "Articuleze" femoral heads. Identification of the original surface is vital in order to accurately determine the wear patterns. In the vast majority of female tapers an original section remains as male tapers (trunnions) do not routinely engage with the full length of the female surface. A customised programme was written using Mitutoyo 'MCOSMOS' software to measure the taper surfaces. This customised programme works in three main stages. The first stage identifies the initial coordinate system. The second stage generates a perfect theoretical cone representing the original perfect unworn surface. The third stage measures the entire surface and compares the data points with the perfect cone to determine any deviations, which represent wear depths, which are summed to calculate volumetric wear. The technique and validation process has been published previously (Bone et al., 2015; Langton et al., 2011b; Langton et al., 2014; Lord et al., 2011).

Briefly, after the co-ordinate data was measured by the CMM, the individual data points were read into a Matlab program (The Mathworks, Inc.). First, the relevant data was extracted and split into matrices representing the Cartesian co-ordinates. These three matrices were used to create a three dimensional representation of the sample. In order to calculate linear wear depths, the distance from each measured point to the centreline of an ideal cone was calculated using the "Pythagoras' Theorem". This original cone was positioned at the time of scanning and all measurements were taken relative to it. The expected distance from the centreline of the cone to each point if the cone were unworn was also calculated. The difference between expected distance and measured distance gave linear wear depths. Once linear wear depths were known, the volumetric wear loss was calculated by multiplying the area of each gridsquare (with a maximum size of $1.57 \mathrm{~mm}$ ) by the mean depths of the four measured points at its corners, as per the method described previously (Langton et al., 2014). 


\section{Results}

The wear evolutions and wear rates for the large taper mismatches are presented up to the load cycle where the taper connection became loose, which was associated with a "largescale rotation" as the femoral stem rotates into the femoral head and exceeds the relative micromotion scale. This large-scale rotation caused difficulties in pairing the nodes and consequent solution convergence. The results for the perfectly matched taper model and the models with lower taper mismatches are presented over the 10 million cycles of loading (equivalent to10 years' activity) where large-scale rotation did not occur.

\subsection{Contact pressure distribution over initial impaction analysis}

The contact pressure distribution at the completion of phase 1 of the wear analysis (Dynamic Impaction analysis) is identical to the contact pressure distribution at commencement of step 2 in phase 2 (see (English et al., 2015)). Figure 4 details the contact pressure distributions along the trunnion surfaces at the last time interval of step 1 in phase 2 of the wear analysis and also the initial area of the taper junction, which is different for different taper mismatches.

Due to the abrupt change in the contact conditions where the end of the trunnion engaged with the taper, the maximum contact pressure values are localised at the proximal edge of the contacting surfaces for the tip-locked models (approximately $350 \mathrm{MPa}$ ). Reducing the taper mismatch reduces this high contact pressure at the proximal edge and increases the contact area. The perfectly matched model (see Figure 4) shows a fairly constant pressure distributed throughout the contacting surfaces, and the contact pressure at the proximal and distal edges is lower than for both the base- and tip-locked models. Again, higher contact pressure values are also distributed at the distal edge of the surface for the base-locked models, which is around 1.7 times lower than for the tip-locked. This shows that reducing the taper mismatches from both tip and base towards the perfectly matched contact surface results in not only a more uniformly distributed contact stress but also an increase in the contacting area. This greater contact area results in better fixation conditions associated with the initial impaction assembly.

\subsection{Wear damage evolution and volumetric wear rate}

Figure 5 shows the evolution of the wear pattern at the femoral head taper surface comparing the perfectly matched interface with tip- and base-locked models illustrated in Table 1. As the wear analysis progresses for all cases the wear depth, as might be expected, increases. The 
variation of volumetric wear rates for different taper mismatches is shown in Figure 6. The volumetric wear rate is increasing as the wear analysis progresses for the extreme taper mismatch models; however, this increase is not linear, as shown in Figure 6. For example, for the 7.8' base-locked taper mismatch the approximate overall average wear rate over 4 million load cycles is around $0.093 \mathrm{~mm}^{3}$ per million cycles, increasing to $0.146,0.330$ and $1.009 \mathrm{~mm}^{3}$ per million load cycles at $5^{\text {th }}, 6^{\text {th }}$ and $7^{\text {th }}$ load cycles respectively.

\subsubsection{Base locked}

Figure 5e, f and g detail the evolution of wear damage over a period associated with 5, 7 and 10 million load cycles for base-locked taper mismatches. It can be seen that significant wear damage occurs at the bottom distal edge of the taper for all cases and this damage is reduced by reducing the taper mismatch to $6^{\prime}$. The wear damage evolves to similar patterns for all base-locked taper mismatches with maximum wear depth determined for 9.12' and 7.8' taper mismatches at 5 and 7 million cycles with a value around $12 \mu \mathrm{m}$, while this maximum wear depth for $6^{\prime}$ taper mismatch is around $5.9 \mu \mathrm{m}$.

Dramatic increases in wear rate can be seen for the model with 9.12' base-locked taper mismatch at $5^{\text {th }}$ million load cycle with a value around $2.960 \mathrm{~mm}^{3}$ per million load cycles, after which large-scale rotation of the femoral stem into the femoral head occurred (see Figure 6). This large-scale rotation occurred after 7 million load cycles for the model with $7.8^{\prime}$ base-locked taper mismatch with a lower wear rate of $1.009 \mathrm{~mm}^{3}$ per million load cycle. Reducing the taper mismatch to $6^{\circ}$ reduces the volumetric wear rate and maintains better fixation between the components by increasing the contact area, so that large-scale rotation did not occur over 10 million load cycles. For the $6^{\prime}$ base-locked taper mismatch, the volumetric wear rate stayed at its lower scale of $0.069 \mathrm{~mm}^{3}$ per million load cycles over 10 million cycles on average.

The moment arm (see Figure 3) causes the wear damage distribution to grow faster towards the tip for base-locked models. As explained, this moment arm is larger for the base-locked models compared to the tip-locked models. This moment dramatically increased the relative micromotion at the taper junction as the solution progressed, which had a significant effect on the magnitude of the wear rates.

\subsubsection{Tip locked}

Figure 5a, b and c detail the wear damage distribution for tip-locked models as the wear analysis progresses. It can be seen that the wear pattern is more circumferentially distributed 
for all cases in this category and is not growing towards the base as fast as the base-locked cases. This is mainly due to the shorter moment arm that occurs at the contact interface. Figure 5a shows a fairly uniform wear damage distributed for the 10.8' tip-locked taper mismatch with a maximum wear depth value of $7.8 \mu \mathrm{m}$ at the proximal edge. Although the wear depth is lower than in the corresponding base-locked model, the very short contact interface causes the model to lose fixation at $7^{\text {th }}$ million load cycle due to the large-scale rotation. For the 7.8' tip-locked taper mismatch, the overall average wear depth is around $5.6 \mu \mathrm{m}$ after 9 million load cycles (see Figure 5b). Similarly, as shown in Figure 5c, the overall wear depth was determined for the $6^{\prime}$ tip-locked taper mismatch at 10 million cycles with an average value around $3.5 \mu \mathrm{m}$, while the large-scale rotation had not yet occurred.

The volumetric wear rates determined for the tip-locked cases were relatively low compared to the base-locked models (see Figure 6). The maximum volumetric wear rate is 0.218 and $0.101 \mathrm{~mm}^{3}$ per million load cycles at $7^{\text {th }}$ and $9^{\text {th }}$ million load cycles for the $10.8^{\prime}$ and $7.8^{\prime}$ taper mismatches respectively. The average volumetric wear rate for the $6^{\prime}$ tip-locked model over 10 million load cycles is around $0.0569 \mathrm{~mm}^{3}$ per million load cycles.

Contrary to the base-locked models, in the tip-locked models the wear damage remains at the area close to the proximal edge of the contact. Furthermore, due to the shorter moment arm than in the base-locked cases, the relative micromotion does not increase significantly. As such, the dramatic increases that happened for the base-locked cases are much less for tiplocked cases. However, as the majority of the area experiences more destructive damage under a shorter contact area, large-scale rotation occurred at $7^{\text {th }}$ and $9^{\text {th }}$ million load cycles for $10.8^{\prime}$ and 7.8' taper mismatches respectively, and are expected to occur for the model with $6^{\prime}$ taper mismatch at a point above 10 million load cycles.

\subsubsection{Matched interfaces}

As explained, reducing the taper mismatch reduces the wear damage and volumetric wear rate. For matched interfaces, the wear pattern is distributed more uniformly at the taper surfaces. The maximum wear depth occurs at the distal edge of the contact with a value of 6.2 $\mu \mathrm{m}$ (see Figure $5 \mathrm{~d}$ ) and the volumetric wear rate is an average of $0.077 \mathrm{~mm}^{3}$ per million load cycles over 10 million loading cycles. It can be seen in Figure 6 that the initial wear rates for the perfectly matched model are slightly higher than both the tip- and base-locked mismatches. Although the initial wear rate is higher for the zero taper mismatch because it has more area in contact and subsequently a larger interface, the fixation is better maintained 
and the stability of the taper junction is higher. This is due to the reduction in the value of the relative micromotion at the taper junction.

\subsection{Total volume loss}

Figure 7 shows the total volume loss after completion of the analyses comparing the perfectly matched analysis with base- and tip-locked taper mismatches. It should be noted that the total volume losses presented for different taper mismatches are over different load cycles. For example, over the period of 5 million loading cycles the total material loss for the 9.12' base-locked taper mismatch is $4.794 \mathrm{~mm}^{3}$. As the taper mismatch reduces, this total material loss is 1.858 and $0.693 \mathrm{~mm}^{3}$ over 7 and 10 million loading cycles for the $7.8^{\prime}$ and $6^{\prime}$ cases respectively. Considering the perfectly matched model over the 10 million loading cycles, it can be seen that the total volumetric loss is slightly higher than the model with $6^{\circ}$ taper mismatch with a value of $0.766 \mathrm{~mm}^{3}$. Figure 7 shows relatively lower total material loss over time for the tip-locked cases, while this value was obtained over a shorter area of contact with the destructive wear damage shown in Figure 5.

\subsection{CMM wear measurement of retrieved femoral tapers}

The finite element wear analyses presented in this study, both wear pattern damage and volumetric wear rates, were seen to be in good agreement with CMM measurement of the wear damage occurring on retrieved prostheses. A total of 54 Articuleze femoral heads were available for inspection, all were $36 \mathrm{~mm}$ in diameter and all had been coupled with Ti Corail femoral stems (see Table 3). The majority of the components were revised due to adverse reactions to metal debris. It was not possible to measure the trunnion angle of the femoral stems as most of the femoral stems were left in vivo. As such, the trunnion angle was based on the work by Brock et al. (2015) which reported a range of $5^{\circ} 33^{\prime}$ to $5^{\circ} 47^{\prime}$ for 72 Corail trunnions. Therefore, a possible taper mismatch variation of $9^{\prime}$ tip-locked to $10.8^{\prime}$ baselocked was calculated. However, the average possible taper mismatch of the 54 Articuleze samples and their variation would suggest that most of the couplings would have a taper mismatch of around $1.87^{\prime}$ to a large base-locked $\left(9.07^{\prime}\right.$ ) with a very low probabilty of a tiplocked coupling. As such, we were unable to identify any large tip-locked examples, however, from taper and trunnion measurements it is possible that a large tip locked taper mismatch might occur.

Table 3 details the average linear and volumetric wear rates along with their variations of all 54 Articuleze samples. Although the time in vivo of the retrievals were available, it was not 
possible to know the actual individual load history and the variation of wear rates over time. As such the wear rates presented in Table 3 were based on the total material loss per year in vivo. It can be seen that the total material loss over a range of possible taper mismatches is in a wide range of 0.102 to $15.730 \mathrm{~mm}^{3}$, however, the average material loss is $2.881 \mathrm{~mm}^{3}$. The volumetric wear rate starts from 0.020 up to $2.241 \mathrm{~mm}^{3} / \mathrm{yr}$ with an average value of 0.550 $\mathrm{mm}^{3} / \mathrm{yr}$. The maximum linear wear depth ranges from 0.100 to $62.030 \mu \mathrm{m}$, with an average value of $18.813 \mu \mathrm{m}$.

Table 4 compares the average volumetric wear rate and its range which is based on different taper mismatches obtained from FE wear analyses and CMM measurments over time. It can be seen in Table 4 that the range of volumetric wear rates obtained from FE wear analyses are closely comparable to the values obtained from CMM measurment of the retrivals. The slight difference in computational prediction with the CMM measurements specifically at $3^{\text {rd }}$ and $4^{\text {th }}$ million load cycles is likley due to the individual variation in loading conditions and activity levels related to the explants. For example, a 45-fold difference between the least and most active patients fitted with hip or knee implants has been reported previously (Schmalzried et al., 1998).

The majority of retrieved femoral heads were found to have patterns of wear damage remarkably similar in appearance to those from the FE analyses. This correlation not only helps to validate the FE model but to also validate the assumptions behind it, for example that walking is of value as a fundamental condition to consider. Figure 8 shows wear maps of three retrieved Articuleze heads which had been used with Corail stems. In Figure 8 the wear damage has been categorised as severe (greater than $10 \mu \mathrm{m}$ ), moderate (around $5 \mu \mathrm{m}$ ) and minor (less than $1 \mu \mathrm{m}$ ) in order to allow comparison with the different stages of the FE wear analysis. Figure 8a shows an Articuleze femoral head with $5^{\circ} 39^{\prime}$ taper angle which was in service for 4 years and probably mated with a stem of around $5^{\circ} 40^{\prime}$ trunnion angle to produce a resulting taper mismatch of around 1' . The wear pattern of FE wear analysis with zero taper mismatch (Figure 5) shows a similar wear pattern to this explant. Moreover, the CMM measurement showed a volumetric wear rate of $0.05 \mathrm{~mm}^{3} / \mathrm{yr}$ which is compairable with FE wear simulation at $4^{\text {th }}$ million load cycle of $0.06 \mathrm{~mm}^{3} / \mathrm{yr}$. Figure $8 \mathrm{~b}$ shows femoral heads with $5^{\circ} 36^{\prime}$ and $5^{\circ} 38^{\prime}$ taper angles which were in service for 7 and 4.25 years respectively. Based on the wear patterns illustrated, these samples could have been mated with a trunnion angle of around $5^{\circ} 45^{\prime}$ resulting in a taper mismatch of around $9^{\prime}$ and $7^{\prime}$, 
both base-locked. The CMM gave a volumetric wear rate of 1.40 and $1.12 \mathrm{~mm}^{3} / \mathrm{yr}$. These are comparable with the FE wear models with $7.8^{\prime}$ and 9.12' at $7^{\text {th }}$ and $4^{\text {th }}$ million load cycles with volumetric wear rates of 1.15 and $1.25 \mathrm{~mm}^{3} / \mathrm{yr}$ and with similar wear patterns (Figure 5).

The wear patterns and wear rates determined in our study are similar to those obtained by Nassif et al. (2014) for measurments obtained from 23 retrived $\mathrm{CoCr}$ femoral heads with varying taper angles of $5^{\circ} 24^{\prime}$ to $5^{\circ} 48^{\prime}$. Nassif et al. (2014) used a high-resolution confocal measurment (RedLux) to measure linear and volumetric wear rates at the taper surfaces. The time in vivo ranged between 1.6 - 4.5 years with a maximum volumetric wear rate of approximately $1 \mathrm{~mm}^{3} / \mathrm{yr}$. They presented three different general patterns of material loss. The computational wear analysis shown in Figure 5 in the present study for matched, base- and tip-locked models are show excellent agreement with the results presented by Nassif et al. (2014).

The volumetric wear ranges obtained from the FE wear analyses show high wear rates (over $2.960 \mathrm{~mm}^{3} / \mathrm{yr}$ ) for larger taper mismatches and it can be seen that reducing the taper mismatch could significantly reduce the volumetric wear rates at taper junction (down to $0.031 \mathrm{~mm}^{3} / \mathrm{yr}$ ).

\section{Discussion}

It is known that design variables such as head diameter, head offset, material combination and taper angles have a significant effect on taper debris generation in THRs (Bone et al., 2015; Jani et al., 1997; Langton et al., 2012; Schmidt et al., 1997). There is inevitable variability in the manufacturing tolerances for the taper and trunnion cone angles of these THRs. There are also no internationally agreed standards for the manufacturing tolerances or surface finishes of such tapers and trunnions. From failures of contemporary THRs, it has been shown that the area of concern is the taper junction of the prostheses (Bishop et al., 2013; Langton et al., 2012; Munir et al., 2015; Shareef and Levine, 1996).

The finite element model and results presented here show excellent agreement with retrievals of the same materials and similar dimensions. Therefore the model has been shown to be valid. One important point to note, is that the model is based purely on fretting wear. It does not include corrosion. Yet the model produces outputs which match clinical retrievals in terms of wear rates and positions of material loss. Therefore corrosion may not be the key cause of material loss at the taper trunnion junction, as has been claimed (Nassif et al., 2014; 
Osman et al., 2016). However, we accept that once metallic wear debris is produced, the effect will likely be that this relatively small debris may be subject to corrosive processes.

From this computational study, we identified that in order to minimise the wear debris generation at the taper junction of THRs, the cone angle of the taper and trunnion should be manufactured with a maximum taper mismatch of $6^{\prime}$. Shorter lower contact offset (shorter contact area below the centre of rotation at taper junction, see Figure 3) would also improve the design and reduce the relative micromotion with a subsequent reduction in volumetric wear rate. It should be noted that, although the wear rates are lower for tip-locked taper mismatches (see Figure 6 and Table 3), this result needs to be treated with caution as there are lower contact surface offsets for this category as shown in Figure 3. Further study is required to investigate the effect of the contact surface offsets.

A limitation to this study is related to the patients' activity. Although the duration of the explants in service were available, it was impossible to prove the actual load history undertaken based on the patients' activity. This could be one of the reasons for the slight differences in computational prediction with the CMM measurements. Another limitation to this study is related to the effect of the surface roughness on the wear rate. We acknowledge that the (grooved) trunnion stem could have effect on the wear rate at the taper-trunnion junction; however, this factor is separate to the effect of the taper mismatch and a large taper mismatch will still be a key factor for a high wear rate at the taper junction. Further investigation is required to consider the effect of the surface roughness on the wear rates at the taper junction of THRs and will form the basis of a future study. Finally, the wear fraction used in this study is based on the theory of titanium hardening in vivo, which happens where the wear depth reaches to around $0.15 \mu \mathrm{m}$ (Moharrami et al., 2013). Although this wear depth occurs at an early stage of the wear analysis, further investigation is required to consider varying the wear fraction during the wear analysis.

\section{Conclusion}

In order to improve the design of hip implants and increase their longevity, it is important to investigate the effects of different design variations. The custom wear algorithm developed and described in this paper was used to investigate the effects of different taper-trunnion angle mismatches on the evolution of the wear rates and wear damage. A series of computational simulations using this wear algorithm were undertaken to determine the optimum taper and trunnion cone angle tolerances to reduce the wear rate at this interface. 
From this FE wear analysis it is seen that, if a large taper mismatch associated with engineering tolerances transpires, the wear rates would initially be lower due to the shorter surface area in contact. However, due to the rapid weakening of the fixation between the components and subsequent increase in relative micromotion, a high wear rate and damage would occur at this junction. Although with zero taper mismatch the wear rate is initially slightly higher due to the larger contact area and subsequent larger interface, the wear pattern is more uniform and the effect of initial fixation will remain longer at the junction, which serves to reduce wear over time. The contact surface offset (see Figure 3) has a significant effect on the wear damage and also on the volumetric wear loss. It has been shown that upper contact offset has a shorter moment arm, which reduces the relative micromotion and leads to a reduction in volumetric wear rate.

The FE model was validated against measurements from a series of 54 explants and an excellent match in terms of wear depths, wear volumes and wear patterns was obtained. This computational analysis was able to model fretting wear over time and could provide a benchmark to help the orthopaedic industry to improve the design of modular hip implants, for the concomitant benefit of patients.

\section{References}

2016. National Joint Registry, 13th annual report for England, Wales, Northern Ireland and the Isle of Man.

Anissian, H.L., Stark, A., Gustafson, A., Good, V., Clarke, I.C., 1999. Metal-on-metal bearing in hip prosthesis generates 100 -fold less wear debris than metal-on-polyethylene. Acta Orthopaedica 70, 578-582.

Atwood, S.A., Patten, E.W., Bozic, K.J., Pruitt, L.A., Ries, M.D., 2010. Corrosion-induced fracture of a double-modular hip prosthesis. The Journal of Bone \& Joint Surgery 92, 15221525 .

Bergmann, G., Deuretzbacher, G., Heller, M., Graichen, F., Rohlmann, A., Strauss, J., Duda, G., 2001. Hip contact forces and gait patterns from routine activities. Journal of biomechanics 34, 859-871.

Bishop, N., Witt, F., Pourzal, R., Fischer, A., Rütschi, M., Michel, M., Morlock, M., 2013. Wear patterns of taper connections in retrieved large diameter metal-on-metal bearings. Journal of Orthopaedic Research 31, 1116-1122.

Bobyn, J.D., Dujovne, A.R., Krygier, J.J., Young, D.L., 1993. Surface analysis of the taper junctions of retrieved and in vitro tested modular hip prostheses. Biological Materials and Mechanical Considerations of Joint Replacement. New York, NY: Raven Press Ltd, 287-301. Bone, M.C., Sidaginamale, R.P., Lord, J.K., Scholes, S.C., Joyce, T.J., Nargol, A.V., Langton, D.J., 2015. Determining material loss from the femoral stem trunnion in hip arthroplasty using a coordinate measuring machine. Proceedings of the Institution of Mechanical Engineers, Part H: Journal of Engineering in Medicine 229, 69-76. Brock, T.M., Sidaginamale, R., Rushton, S., Nargol, A.V.F., Bowsher, J.G., Savisaar, C., Joyce, T.J., Deehan, D.J., Lord, J.K., Langton, D.J., 2015. Shorter, rough trunnion surfaces 
are associated with higher taper wear rates than longer, smooth trunnion surfaces in a contemporary large head metal-on-metal total hip arthroplasty system. Journal of Orthopaedic Research 33, 1868-1874.

Cooper, H.J., Della Valle, C.J., Berger, R.A., Tetreault, M., Paprosky, W.G., Sporer, S.M., Jacobs, J.J., 2012. Corrosion at the head-neck taper as a cause for adverse local tissue reactions after total hip arthroplasty. The Journal of Bone \& Joint Surgery 94, 1655-1661. English, R., Ashkanfar, A., Rothwell, G., 2015. A computational approach to fretting wear prediction at the head-stem taper junction of total hip replacements. Wear 338, 210-220. English, R., Ashkanfar, A., Rothwell, G., 2016. The effect of different assembly loads on taper junction fretting wear in total hip replacements. Tribology International 95, 199-210. Fessler, H., Fricker, D., 1989. Friction in femoral prosthesis and photoelastic model cone taper joints. Proceedings of the Institution of Mechanical Engineers, Part H: Journal of Engineering in Medicine 203, 1-14.

Fouvry, S., Liskiewicz, T., Kapsa, P., Hannel, S., Sauger, E., 2003. An energy description of wear mechanisms and its applications to oscillating sliding contacts. Wear 255, 287-298.

Hallab, N.J., Messina, C., Skipor, A., Jacobs, J.J., 2004. Differences in the fretting corrosion of metal-metal and ceramic-metal modular junctions of total hip replacements. Journal of Orthopaedic Research 22, 250-259.

Jani, S.C., Sauer, W.L., McLean, T.W., Lambert, R.D., Kovacs, P., 1997. Fretting corrosion mechanisms at modular implant interfaces, Modularity of Orthopedic Implants. ASTM International.

Joyce, T.J., Langton, D.J., Jameson, S.S., Nargol, A.V.F., 2009. Tribological analysis of failed resurfacing hip prostheses and comparison with clinical data. Proceedings of the Institution of Mechanical Engineers, Part J: Journal of Engineering Tribology 223, 317-323.

Langton, D., Jameson, S., Joyce, T., Gandhi, J., Sidaginamale, R., Mereddy, P., Lord, J., Nargol, A., 2011a. Accelerating failure rate of the ASR total hip replacement. Journal of Bone \& Joint Surgery, British Volume 93, 1011-1016.

Langton, D., Sidaginamale, R., Lord, J., Nargol, A., Joyce, T., 2012. Taper junction failure in large-diameter metal-on-metal bearings. Bone and Joint Research 1, 56-63.

Langton, D.J., Hashmi, M., Green, S., O’Brien, S., Duffy, P., Scott, S., Shaw, N., 2016. Investigation of taper failure in a contemporary metal on metal hip arthroplasty system through examination of explanted prosthesis. Accepted by the Journal of Bone \& Joint Surgery.

Langton, D.J., Joyce, T.J., Mangat, N., Lord, J., Van Orsouw, M., De Smet, K., Nargol, A.V.F., 2011b. Reducing metal ion release following hip resurfacing arthroplasty. Orthopedic Clinics of North America 42, 169-180.

Langton, D.J., Sidaginamale, R.P., Holland, J.P., Deehan, D., Joyce, T.J., Nargol, A.V.F., Meek, R.D., Lord, J.K., 2014. Practical considerations for volumetric wear analysis of explanted hip arthroplasties. Bone and Joint Research 3, 60-68.

Lindgren, J.U., Brismar, B.H., Wikstrom, A.C., 2011. Adverse reaction to metal release from a modular metal-on-polyethylene hip prosthesis. Journal of Bone \& Joint Surgery, British Volume 93, 1427-1430.

Liskiewicz, T., Fouvry, S., 2005. Development of a friction energy capacity approach to predict the surface coating endurance under complex oscillating sliding conditions. Tribology international 38, 69-79.

Lord, J.K., Langton, D.J., Nargol, A.V.F., Joyce, T.J., 2011. Volumetric wear assessment of failed metal-on-metal hip resurfacing prostheses. Wear 272, 79-87.

Magaziner, R., Jain, V., Mall, S., 2008. Wear characterization of Ti-6Al-4V under frettingreciprocating sliding conditions. Wear 264, 1002-1014. 
Mao, X., Tay, G.H., Godbolt, D.B., Crawford, R.W., 2012. Pseudotumor in a well-fixed metal-on-polyethylene uncemented hip arthroplasty. The Journal of Arthroplasty 27, 493e413.

Marlowe, D.E., Parr, J.E., Mayor, M.B., 1997. Modularity of orthopedic implants. ASTM International.

Matthies, A.K., Racasan, R., Bills, P., Blunt, L., Cro, S., Panagiotidou, A., Blunn, G., Skinner, J., Hart, A.J., 2013. Material loss at the taper junction of retrieved large head metalon-metal total hip replacements. Journal of Orthopaedic Research 31, 1677-1685.

McGrory, B.J., Morrey, B.F., Cahalan, T.D., An, K.N., Cabanela, M.E., 1995. Effect of femoral offset on range of motion and abductor muscle strength after total hip arthroplasty.

Journal of Bone \& Joint Surgery, British Volume 77, 865-869.

Moharrami, N., Langton, D., Sayginer, O., Bull, S., 2013. Why does titanium alloy wear cobalt chrome alloy despite lower bulk hardness: A nanoindentation study? Thin Solid Films 549, 79-86.

Munir, S., Walter, W.L., Walsh, W.R., 2015. Variations in the trunnion surface topography between different commercially available hip replacement stems. Journal of Orthopaedic Research 33, 98-105.

Nassif, N.A., Nawabi, D.H., Stoner, K., Elpers, M., Wright, T., Padgett, D.E., 2014. Taper design affects failure of large-head metal-on-metal total hip replacements. Clinical Orthopaedics and Related Research ${ }^{\circledR} 472,564-571$.

Osman, K., Panagiotidou, A.P., Khan, M., Blunn, G., Haddad, F.S., 2016. Corrosion at the head-neck interface of current designs of modular femoral components. Bone Joint J 98, 579584.

Panagiotidou, A., Meswania, J., Hua, J., Muirhead-Allwood, S., Hart, A., Blunn, G., 2013. Enhanced wear and corrosion in modular tapers in total hip replacement is associated with the contact area and surface topography. Journal of Orthopaedic Research 31, 2032-2039.

Schmalzried, T.P., Szuszczewicz, E.S., Northfield, M.R., Akizuki, K.H., Frankel, R.E., Belcher, G., Amstutz, H.C., 1998. Quantitative Assessment of Walking Activity after Total Hip or Knee Replacement*. The Journal of Bone \& Joint Surgery 80, 54-59.

Schmidt, A.H., Loch, D.A., Bechtold, J.E., Kyle, R.F., 1997. Assessing Morse taper function: the relationship between impaction force, disassembly force, and design variables.

Modularity of Orthopedic Implants 1301, 114.

Shareef, N., Levine, D., 1996. Effect of manufacturing tolerances on the micromotion at the Morse taper interface in modular hip implants using the finite element technique.

Biomaterials 17, 623-630.

Zhang, T., Harrison, N., McDonnell, P., McHugh, P., Leen, S., 2013. A finite element methodology for wear-fatigue analysis for modular hip implants. Tribology International 65, 113-127. 


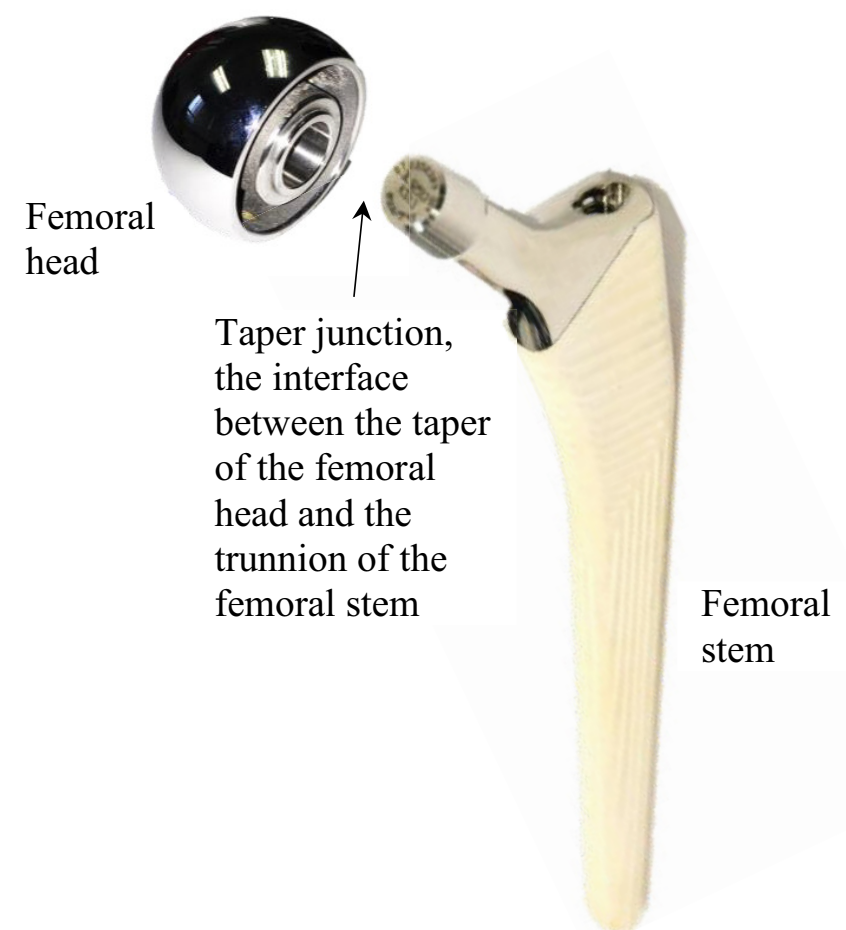

Figure 1: Ti Corail stem and $\mathrm{CoCr}$ femoral head 
Table 1: Taper and trunnion cone angles and associated mismatches.

\begin{tabular}{l|ccc|c|ccc}
\hline & \multicolumn{3}{|c|}{ Tip locked } & Matched & \multicolumn{2}{c}{ Base locked } \\
\hline Trunnion & $5^{\circ} 37.2^{\prime}$ & $5^{\circ} 42.6^{\prime}$ & $5^{\circ} 36^{\prime}$ & $5^{\circ} 39^{\prime}$ & $5^{\circ} 42^{\prime}$ & $5^{\circ} 34.8^{\prime}$ & $5^{\circ} 43.2^{\prime}$ \\
Taper & $5^{\circ} 48^{\prime}$ & $5^{\circ} 34.8^{\prime}$ & $5^{\circ} 42^{\prime}$ & $5^{\circ} 39^{\prime}$ & $5^{\circ} 36^{\prime}$ & $5^{\circ} 42.6^{\prime}$ & $5^{\circ} 34.1^{\prime}$ \\
\hline Mismatch & $10.8^{\prime}$ & $7.8^{\prime}$ & $6^{\prime}$ & 0 & $6^{\prime}$ & $7.8^{\prime}$ & $9.1^{\prime}$ \\
$\begin{array}{l}\text { Head-Stem } \\
\text { assembly }\end{array}$ & & &
\end{tabular}




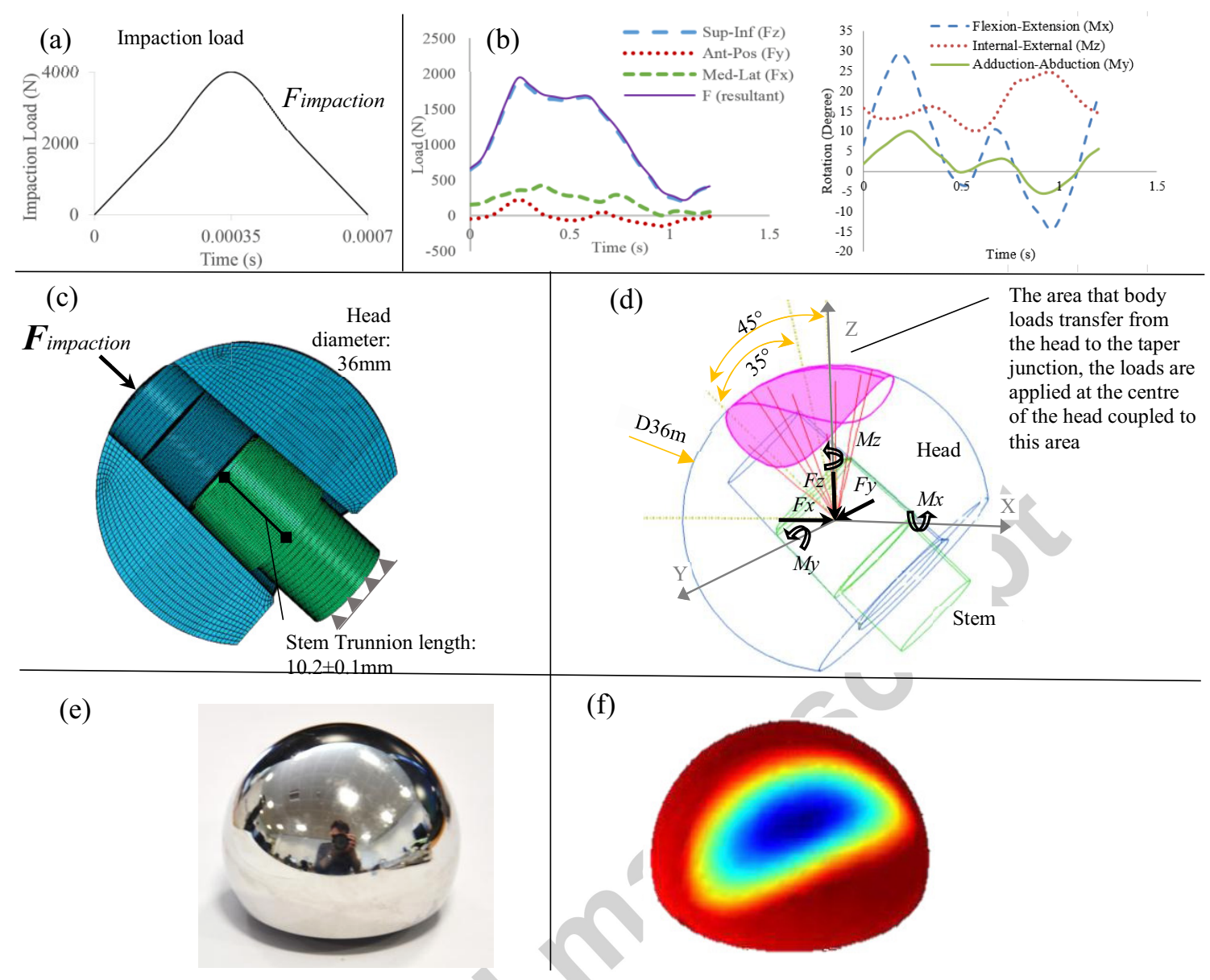

Figure 2: (a) Impaction load, (b) walking loads and rotations, (c) mesh distribution,(d) loading, boundary condition and schematic presentation of the finite element model (e) a worn $36 \mathrm{~mm} \mathrm{CoCr}$ femoral head and (f) its CMM measurement (dark blue shows the area with maximum wear depth and the dark red area is the unworn area). The purple area shown in (d) is the area where body loads transfer from the head to the taper junction; the loads are applied at the centre of the head coupled to this area, and this area was obtained approximately from the area shown in (f), which is the area of wear on the articulating surface of the femoral head shown in (e). 
Table 2: Material and contact interaction properties

\begin{tabular}{llllllll}
\hline & Material & $\begin{array}{l}\text { Young's } \\
\text { Modulus }(\mathrm{GPa})\end{array}$ & $\begin{array}{l}\text { Poisson } \\
\text { Ratio }\end{array}$ & $\begin{array}{l}\text { Density } \\
\left(\mathrm{kg} / \mathrm{m}^{3}\right)\end{array}$ & $\begin{array}{l}\text { Wear } \\
\text { fraction }\end{array}$ & $\begin{array}{l}\text { Wear } \\
\text { coefficient }\end{array}$ & $\begin{array}{l}\text { Friction } \\
\text { coefficient }\end{array}$ \\
\hline Head & Co-28Cr-6Mo & 210 & 0.30 & 7800 & 0.9 & \multirow{2}{*}{$1.31 \mathrm{e}-8$} & 0.21 \\
Stem & Ti-6Al-4V & 119 & 0.29 & 4400 & 0.1 & & \\
\hline
\end{tabular}




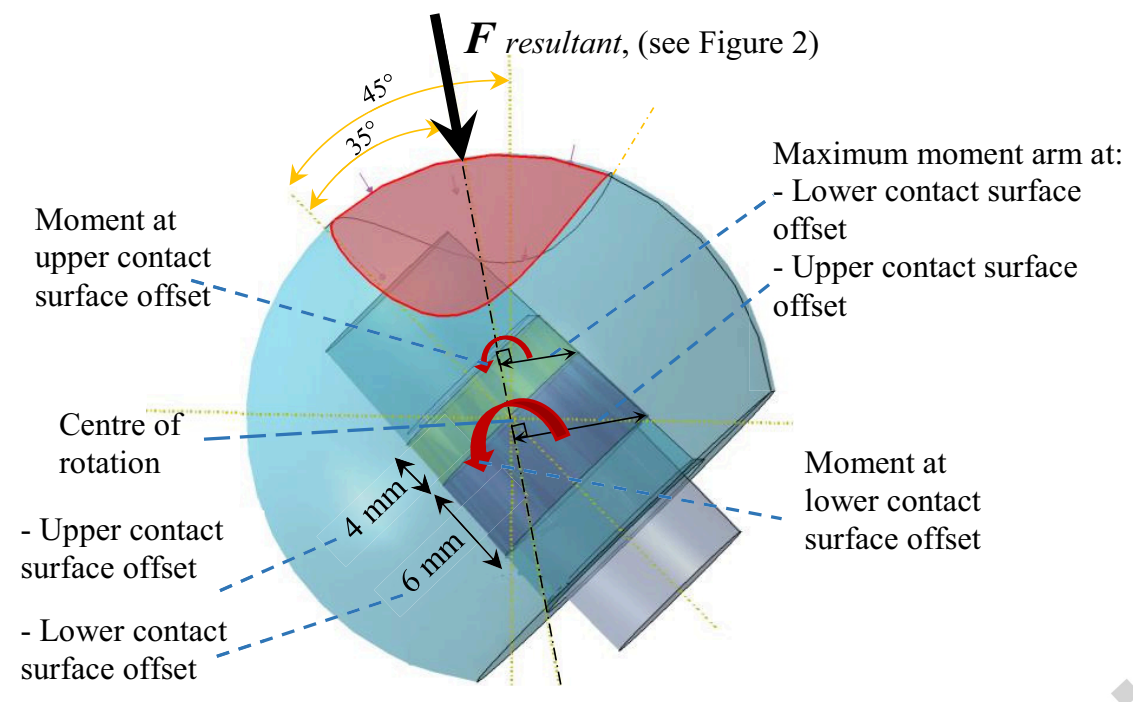

Figure 3: Moment arms at upper and lower contact surface offset 


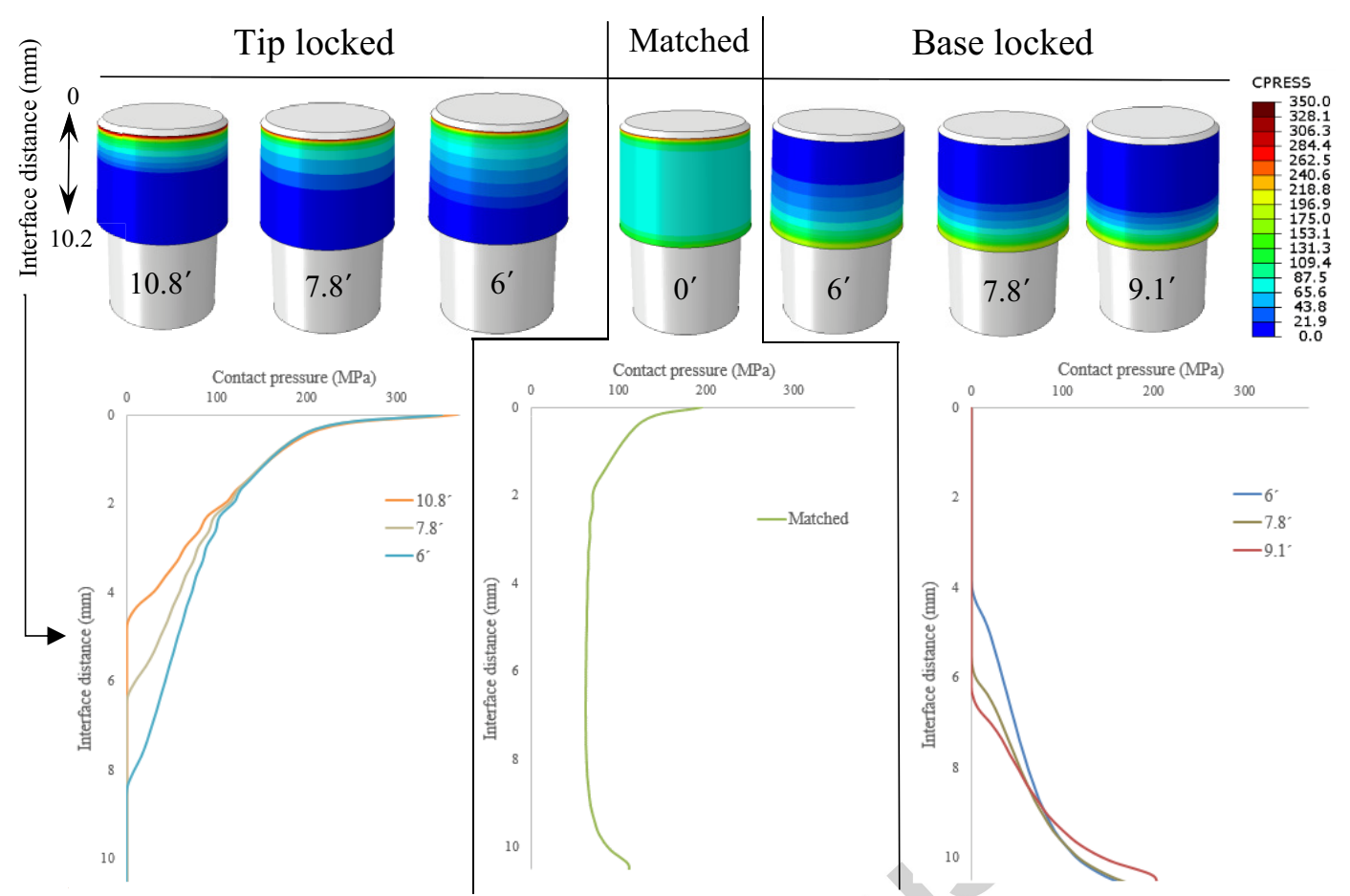

Figure 4: Contact pressure distribution along trunnion surface at the commencement of wear analysis. Amount of mismatch indicated in minutes. 


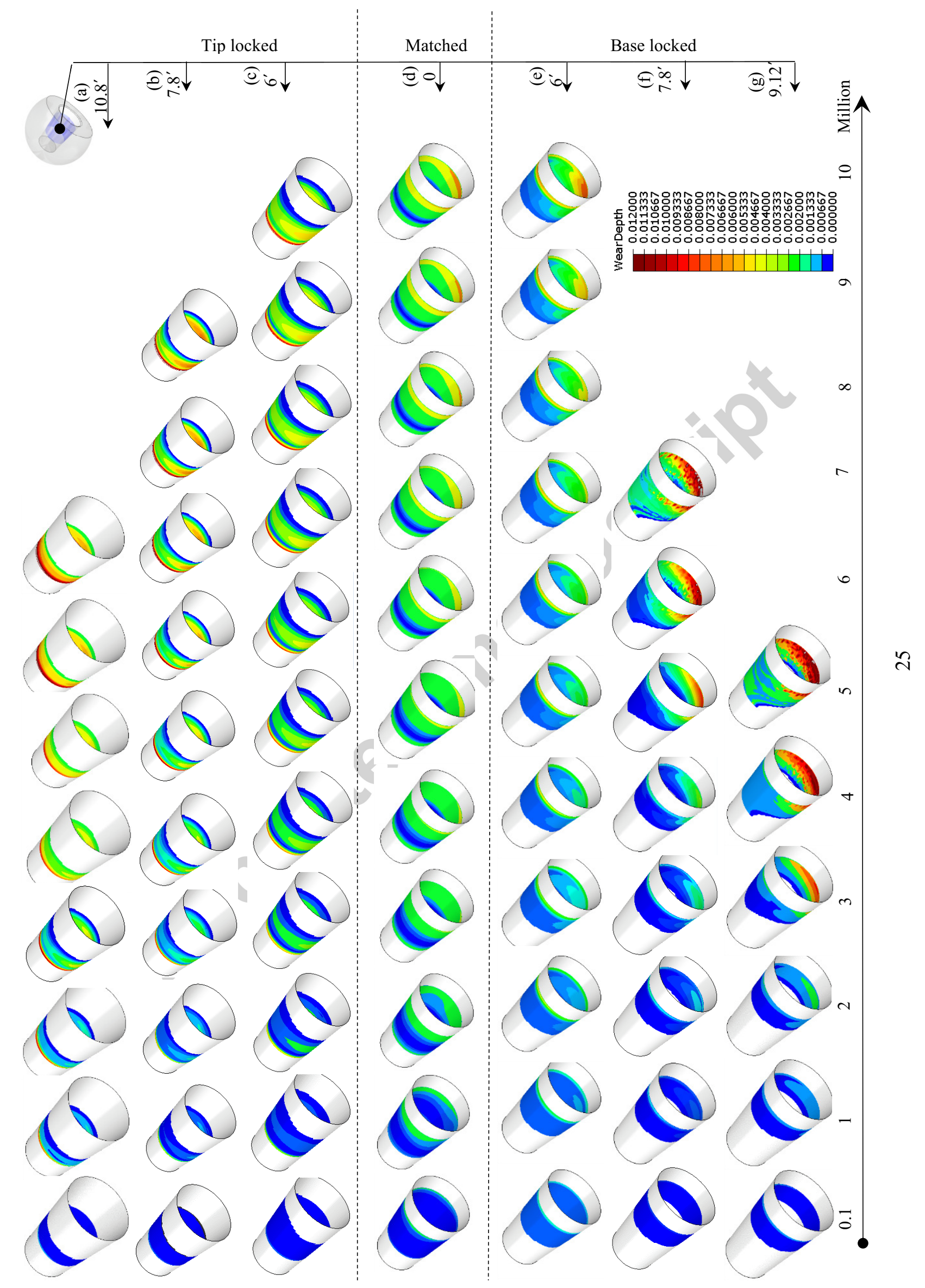




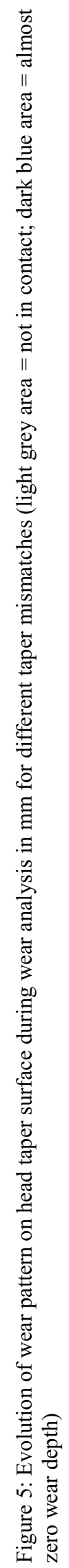




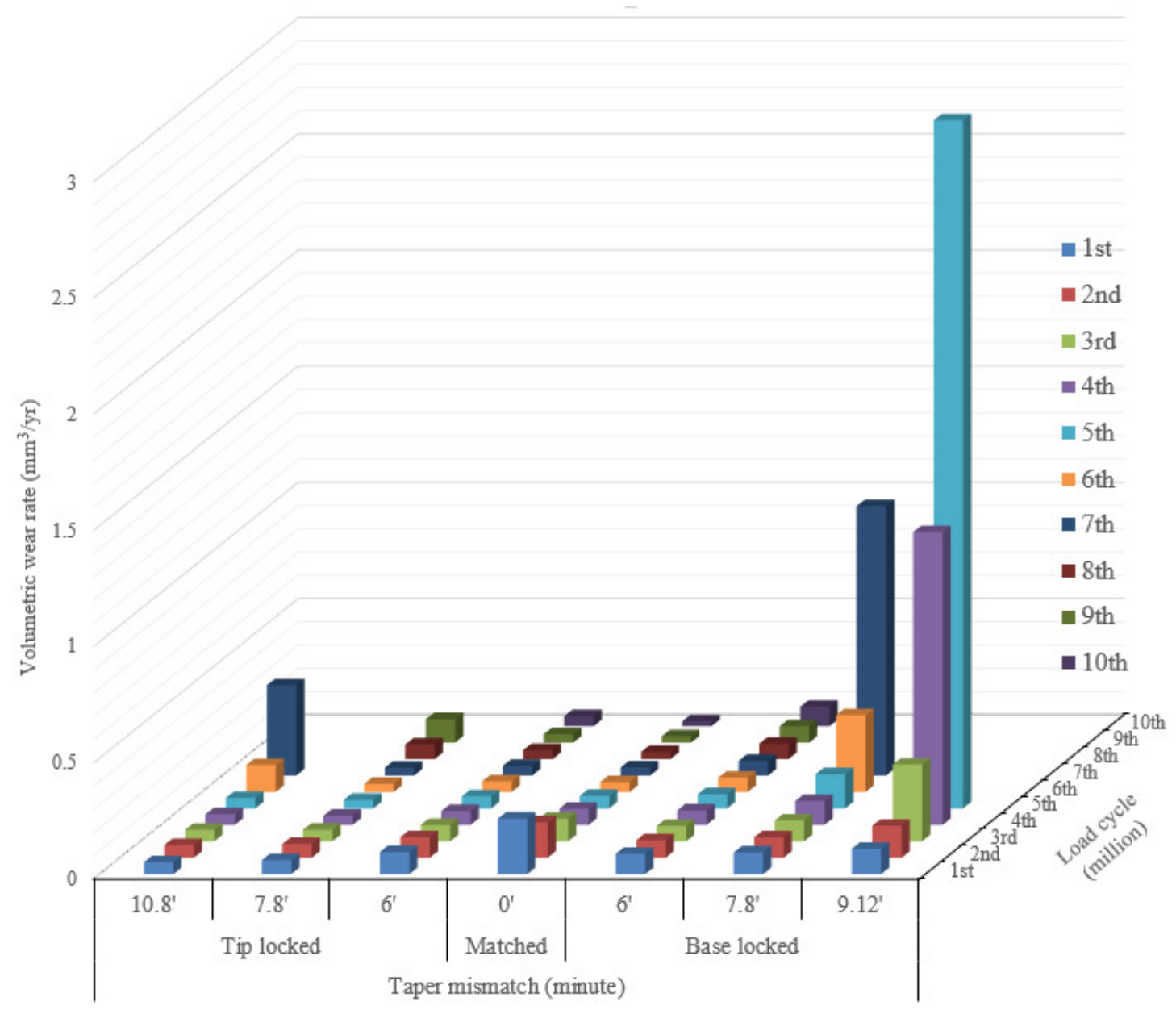

Figure 6: Evolution of volumetric wear rates with respect to different taper mismatches. 


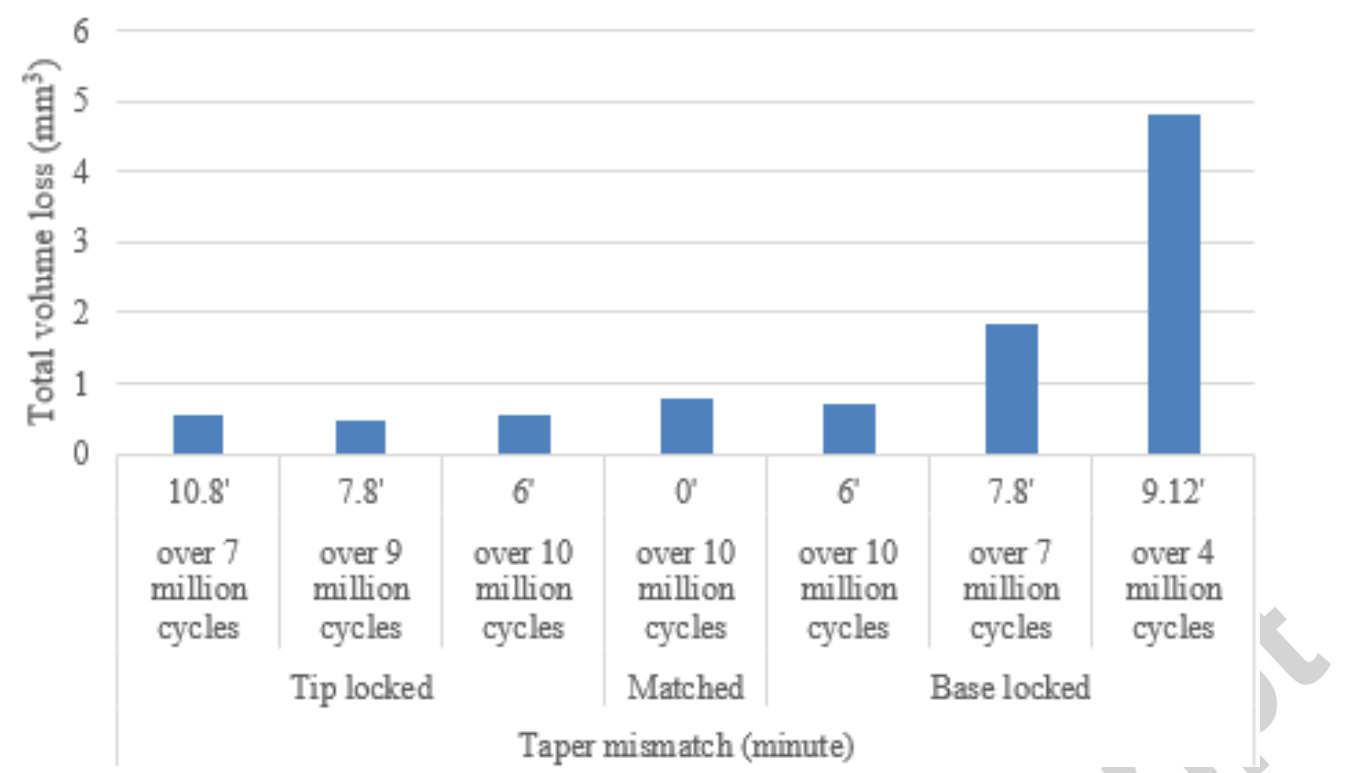

Figure 7: Total volume loss for different taper mismatches. Note that the total volume loss values presented are over different total number of load cycles. 
Table 3: Details of the samples analysed and variation in volumetric and linear wear rates (total of 54 Articuleze femoral head (all 36mm diameter))

\begin{tabular}{|c|c|c|c|}
\hline 54 Articuleze femoral heads & Average & \multicolumn{2}{|c|}{ Range } \\
\hline Time in vivo $(\mathrm{yr})$ & 5.1 & 1.5 & 11.0 \\
\hline \multicolumn{4}{|c|}{ Angle } \\
\hline Taper angle & $5^{0} 38^{\prime}$ & $5^{0} 36.2^{\prime}$ & $5^{0} 42^{\prime}$ \\
\hline Trunnion angle & $5^{0} 40.5^{\prime}$ & $5^{0} 33^{\prime}$ & $5^{0} 47^{\prime}$ \\
\hline $\begin{array}{l}\text { Possible taper mismatch } \\
\text { (average of } 54 \text { samples) }\end{array}$ & base-locked $1.87^{\prime}$ & tip-locked 5.32' & base-locked $9.07^{\prime}$ \\
\hline Possible taper mismatch & base-locked $1.45^{\prime}$ & tip-locked 9' & base-locked $10.8^{\prime}$ \\
\hline \multicolumn{4}{|c|}{ Volumetric wear } \\
\hline Total volume loss $\left(\mathrm{mm}^{3}\right)$ & 2.881 & 0.102 & 15.730 \\
\hline Volumetric wear rate $\left(\mathrm{mm}^{3} / \mathrm{yr}\right)$ & 0.550 & 0.020 & 2.241 \\
\hline \multicolumn{4}{|c|}{ Linear wear depth } \\
\hline Maximum wear depth $(\mu \mathrm{m})$ & 18.813 & 0.101 & 62.030 \\
\hline Maximum linear wear rate $(\mu \mathrm{m} / \mathrm{yr})$ & 3.760 & 0.020 & 12.090 \\
\hline
\end{tabular}


Table 4: Comparing volumetric wear rate and its range for different taper mismatches obtained from FE analyses and CMM measurements.

\begin{tabular}{lll}
\hline & \multicolumn{2}{c}{ Average volumetric wear rate $\left(\mathrm{mm}^{3} / \mathrm{yr}\right)($ range $)$} \\
Year (range of time in vivo) & FEA & CMM \\
\hline 3rd $(2.8-3.5)$ & $0.111(0.048-0.330)$ & $0.297(0.044-0.915)(\mathrm{n}=7)$ \\
4th $(3.7-4.3)$ & $0.233(0.039-1.259)$ & $0.597(0.030-1.301)(\mathrm{n}=10)$ \\
5th $(4.8-5.5)$ & $0.479(0.036-2.960)$ & $0.475(0.021-1.860)(\mathrm{n}=11)$ \\
6th $(5.8-6.5)$ & $0.512(0.035->2.960)$ & $0.556(0.026-2.244)(\mathrm{n}=10)$ \\
7th $(6.6-7.2)$ & $0.670(0.031->2.960)$ & $0.649(0.023-2.270)(\mathrm{n}=9)$ \\
\hline
\end{tabular}




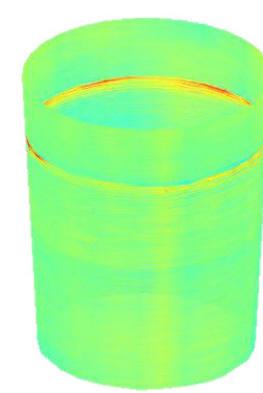

(a) Possible zero taper mismatch
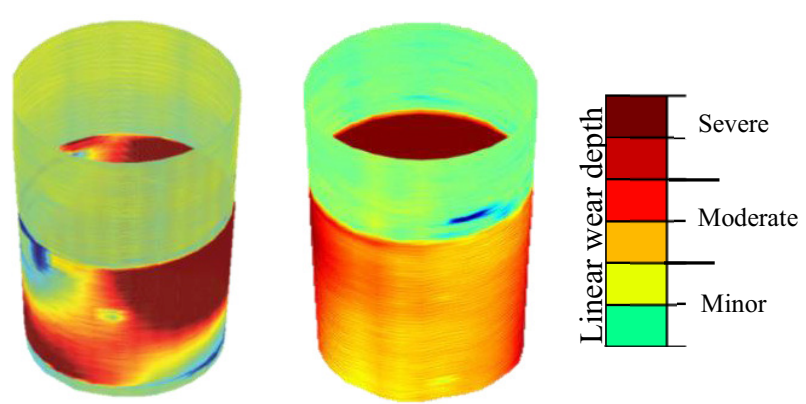

(b) Possible base-locked taper mismatch

Figure 8: CMM wear measurements of typical retrieved Articuleze femoral head taper which had been used with a Corail stem, light green areas represent the original surface and deep red areas indicate areas of maximum wear depth which reaches to $20 \mu \mathrm{m}$ in some measurments.

\section{Highlights}

- An FE wear model was used to analyse the extent of wear damage in hip implants

- Experimental measurement at taper junction of 54 retrievals validated the FE analyses

- The effect of different taper-trunnion mismatches on fretting wear is demonstrated

- A large taper mismatch results in a high wear rate with negative clinical outcomes

- A slight reduction in mismatch to $6^{\prime}$ or less significantly reduced the wear rate 